\title{
Material and Structural Properties of Fiber-Reinforced Resin Composites as Thin Overlay for Steel Bridge Deck Pavement
}

\author{
Hui Zhang $\mathbb{D},{ }^{1,2}$ Chengqi Zhou $\left(\mathbb{D},{ }^{2}\right.$ Kuan Li $\mathbb{D}^{,},{ }^{2}$ Peiwei Gao $\left(\mathbb{D},{ }^{1}\right.$ Youqiang Pan $\left(\mathbb{D},{ }^{2}\right.$ \\ and Zhixiang Zhang $\mathbb{D}^{2}$ \\ ${ }^{1}$ Nanjing University of Aeronautics and Astronautics, Nanjing, Jiangsu 210016, China \\ ${ }^{2}$ Jiangsu SinoRoad Engineering Research Institute, Nanjing, Jiangsu 211806, China \\ Correspondence should be addressed to Peiwei Gao; gpw1963@163.com
}

Received 28 August 2019; Revised 4 November 2019; Accepted 12 November 2019; Published 18 December 2019

Guest Editor: Jian Ouyang

Copyright (C) 2019 Hui Zhang et al. This is an open access article distributed under the Creative Commons Attribution License, which permits unrestricted use, distribution, and reproduction in any medium, provided the original work is properly cited.

\begin{abstract}
Fatigue cracks are main damages to steel bridge deck pavement with thermosetting epoxy asphalt. By combining a high-toughness resin material with fiber woven fabrics, this study formed an ultrathin overlay of fiber-reinforced high-toughness resin to improve cracking resistance of pavement. Through theoretical measurement and bending test, this research studied change laws of bending and tensile properties of epoxy asphalt concrete after fiber reinforcement and analyzed bending strength and the maximum failure strain of beams at different temperatures. Moreover, the reinforcing effects of different fibers were discussed. It is found that bending strength, maximum failure strain, and stiffness modulus of the beams with epoxy asphalt are improved after fiber reinforcement. With the decrease of temperature, after fiber reinforcement, the mode of bending failure of the epoxy asphalt mixture (EAM) changes from brittle fracture into shear failure, accompanied with significant yield phenomenon. Furthermore, organic carbon fiber is sensitive to influences of temperature, while glass fiber is least sensitive to temperature.
\end{abstract}

\section{Introduction}

Steel bridge deck pavement is to pave thin layer structures with thickness of $5 \sim 8 \mathrm{~cm}$ on the orthotropic plates. Due to flexibility of steel bridge deck, there are extremely high application requirements for pavement materials, mainly including coordinated deformation capacity, waterproofness, high strength, and excellent fatigue performance of steel plates [1-3]. At present, typical pavement schemes, such as epoxy asphalt, gussasphalt, and stone matrix asphalt (SMA), are mainly used [4]. Of them, epoxy asphalt materials with higher antirutting performance at high temperature and bending fatigue performance are universally used in China $[5,6]$.

Different from thermoplastic asphalt pavement, because epoxy asphalt is a thermosetting material, cracking as shown in Figure 1, a main type of damages mainly occurs in wheel track bands, longitudinal diaphragms of steel box beams, and ends of U-shaped ribs under long-term load [7, 8]. At present, technologies for preventive maintenance of asphalt pavement have been mainly studied, thus proposing some relative mature schemes, such as fog sealing layer, slurry seal, microsurfacing, and thin overlays. However, at present, there are no mature technologies and materials for timely preventive maintenance of cracks on epoxy asphalt pavement.

The traditional technologies for preventive maintenance of asphalt pavement are mainly based on asphalt materials. Due to limited strength and low bond strength of the materials with epoxy asphalt pavement, peeling and cracking easily appear. The research on the maintenance technology of steel bridge deck pavement started relatively late. There are some researches on cracks, swelling, and patching [9 11] and some achievements in pavement in which the original hot-blended epoxy asphalt is replaced with new coldblended epoxy resin materials are mainly obtained. However, there are few technologies for preventive maintenance of bridge deck. The authors and other researchers have reported the scheme of preventive maintenance of bridge deck using epoxy resin seal $[12,13]$. Because of high requirements for deformation capacity of materials on steel bridge deck pavement, fatigue cracking easily appears when 


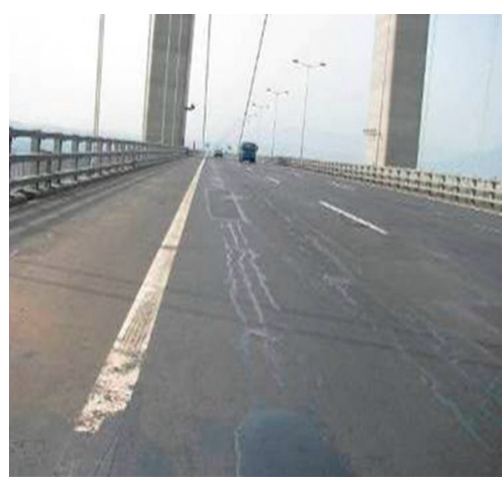

(a)

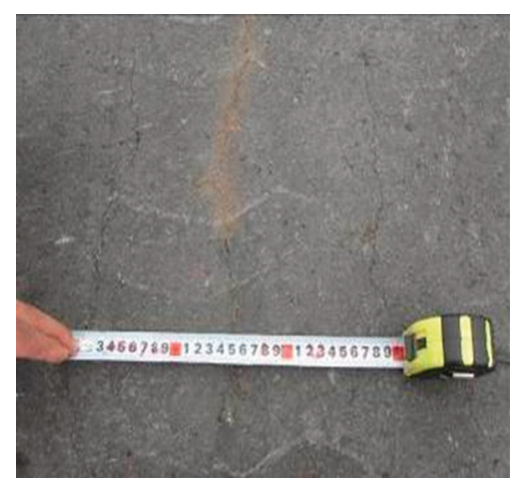

(b)

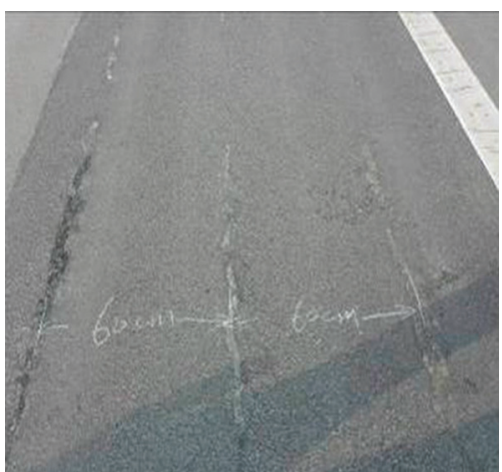

(c)

Figure 1: Fatigue cracks in epoxy asphalt on steel bridge deck pavement.

using the general scheme of epoxy resin and synchronous surface dressing.

In order to further improve tensile resistance of pavement materials, the research results of the fiber-reinforced asphalt mixture have been reported in many literatures, and the optimal mixing amount and performance mechanisms of the polyester fiber in the asphalt mixture have been proposed [14-16]. As composites emerge, researchers have conducted research and made breakthrough in high-temperature performance, vitrification, and fatigue properties of fiber-reinforced resin materials, which makes it possible for the materials to be applied in engineering of the transportation industry [17-19].

Based on a high-toughness resin material and its combination with fiber woven fabrics, the research prepared an ultrathin overlay of fiber-reinforced hightoughness resin with the thickness of only about $5 \mathrm{~mm}$. The overlay enhanced cracking resistance of the existing epoxy pavement, thus extending service life of steel bridge deck pavement with epoxy asphalt. It is expected to provide supports for research and engineering application of technologies for preventive maintenance of steel bridge deck pavement with epoxy asphalt.

\section{Materials and Experimental Methods}

2.1. Experimental Materials. This study used the Bv epoxy asphalt mixture (EAM), which was produced by ChemCo Systems Company in the United States and composed of component A (liquid bisphenol A epoxy resin) and component $\mathrm{B}$ (homogeneous compositions comprising petroleum asphalt and curing agent) with the ratio of 100: 518. Special aggregates for steel bridge deck pavement produced by Jiangsu Maodi Group Co., Ltd. and mineral powder manufactured from limestone in Jurong county, Jiangsu province, China, were utilized. The proportion of mineral aggregates, i.e., 1\# aggregate (with diameter of 10 13 mm), 2\# aggregate (with diameter of $5 \sim 10 \mathrm{~mm}$ ), 3\# aggregate (with diameter of $3 \sim 5 \mathrm{~mm}$ ), 4\# aggregate (with diameter of $1 \sim 3 \mathrm{~mm}$ ), 5\# aggregate (with diameter of $0.075 \sim 1 \mathrm{~mm}$ ), and mineral powder was $2.5 \%: 22.5 \%$ : 21.5\%: $22 \%$ : $23 \%$ : $8.5 \%$. Controlling the resultant gradation according to the median of the gradation range, the results are shown in Table 1 . The asphalt-aggregate ratio was $6.5 \%$.
TABLE 1: The aggregate gradation used in this study.

\begin{tabular}{lcccccc}
\hline & \multicolumn{6}{c}{ Mass percentage of aggregates passing } \\
Mesh $(\mathrm{mm})$ & \multicolumn{6}{c}{ through meshes (square mesh, mm) $(\%)$} \\
& 13.2 & 9.5 & 4.75 & 2.36 & 0.6 & 0.075 \\
\hline $\begin{array}{l}\text { Grading } \\
\text { requirements }\end{array}$ & 100 & $95 \sim 100$ & $65 \sim 85$ & $50 \sim 70$ & $28 \sim 40$ & $7 \sim 14$ \\
$\begin{array}{l}\text { Resultant } \\
\text { gradation }\end{array}$ & 100.0 & 99.7 & 75.2 & 59.3 & 34.5 & 11.0 \\
$\begin{array}{l}\text { Median of } \\
\text { gradation }\end{array}$ & 100.0 & 97.5 & 75.0 & 60.0 & 34.0 & 10.5 \\
\hline
\end{tabular}

The used RPF high-toughness epoxy resin was provided by Jiangsu SinoRoad Transportation Science and Technology Co., Ltd., China, and comprised component A (polyurethanemodified epoxy resin) and component B (fatty amine curing agent) with the ratio of $4: 1$. By referring to the ASTM D6382014 test method, the tensile strength and elongation of hightoughness resin were measured through tensile test. The tensile strength, elongation at fracture, and tensile elastic modulus were $25.2 \mathrm{MPa}, 63.2 \%$, and about $40 \mathrm{MPa}$, respectively, tested at $23 \pm 1^{\circ} \mathrm{C}$ and a stretching rate of $50 \mathrm{~mm} / \mathrm{min}$.

In reference to the ASTM D4541-09 test method, bond performance of high-toughness resin and epoxy asphalt concrete was determined through the pull-off test at room temperature of $23^{\circ} \mathrm{C}$ and high temperature of $70^{\circ} \mathrm{C}$ at a drawing rate of $0.7 \mathrm{MPa} / \mathrm{s}$. The test results are presented in Table 2. At room temperature of $23^{\circ} \mathrm{C}$, the fracture surface in the pull-off test was found at the interface of sealing materials and the mixture, and bond strength of high-toughness resin was $14.65 \mathrm{MPa}$. When temperature rose to $70^{\circ} \mathrm{C}$, the fracture surface was located in the interior of EAM. The fracture surface in the pull-off test is demonstrated in Figure 2. This indicated that there was a strong bond capacity between hightoughness resin and epoxy asphalt concrete.

The utilized fiber cloth included basalt, glass, and carbon in total. The basalt fiber cloth was manufactured by Jiangsu Tianlong Co. Ltd., China, and represented with BF, while glass fiber cloth was produced by Jiangsu Zhongyitong Company, China, and expressed as GF. Moreover, the carbon fiber cloth was from Zhejiang Haining Company, China, expressed as CF. Performance parameters at room temperature of fiber are presented in Table 3. 
TABLE 2: Bond strength of high-toughness resin with epoxy asphalt concrete.

\begin{tabular}{lcc}
\hline Test temperature $\left({ }^{\circ} \mathrm{C}\right)$ & Pull-off strength $(\mathrm{MPa})$ & Fracture surface \\
\hline 23 & 14.65 & Interface between resin and mixture \\
70 & 1.56 & Interior of the mixture \\
\hline
\end{tabular}

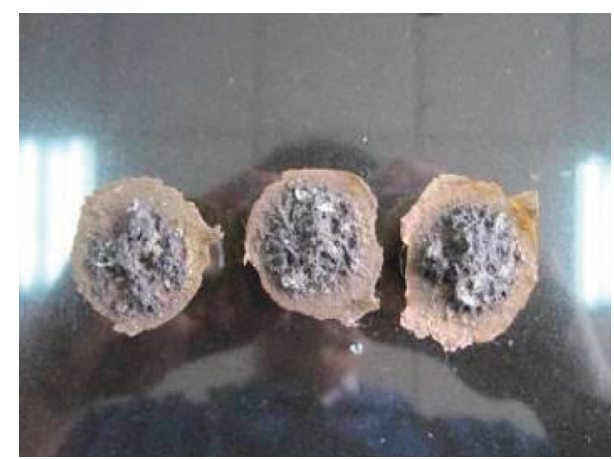

Figure 2: Fracture interface in pull-off test $\left(70^{\circ} \mathrm{C}\right)$.

2.2. Finite Element Simulation. By using the finite element software ABAQUS, mechanics simulation was performed on steel bridge deck pavement with fiber-reinforced epoxy resin-modified asphalt (Figure 3). By referring to boundary parameters and the worst load position in literatures $[9,10]$, the influences of changes of modulus of different fiberreinforced thin resin layers on mechanical response of the original pavement structure were analyzed. The moduli were $3,000,5,000,7,000,9,000,11,000,13,000,15,000,17,000$, 19,000 , and 21,000 MPa. Load was standard axle loading of $100 \mathrm{kN}$ on a single axle with dual tires, and tire pressure was 0.7 MPa. Model parameters are shown in Table 4.

The maximum transverse tensile stress $\sigma$ and strain $\varepsilon$ were selected as indexes of mechanical analysis. The calculation results are displayed in Figure 4. With the increase of modulus of the thin overlay, the maximum tensile stress and strain of the original epoxy asphalt pavement surface significantly decrease. When modulus of the thin overlay increases to $21,000 \mathrm{MPa}$, the maximum tensile stress and strain of the original pavement reduce by about $66.2 \%$ and $64.3 \%$, respectively, in comparison with the pavement without thin overlay. As modulus of the thin overlay rises, the maximum tensile stress of the thin overlay itself remarkably increases, while the maximum tensile strain significantly decreases. When the modulus of the thin overlay increases from 3,000 to $21,000 \mathrm{MPa}$, the maximum tensile stress of the thin overlay rises about $212.6 \%$ while the maximum tensile strain reduces about 53.7\%.

2.3. Specimen Preparation and Experimental Methods. By referring to the EN 12697-33-2007 method of specimens prepared by roller compactor, a rutting plate of the EAM was molded. After molding, the plate was placed in an oven to be cured for $4 \mathrm{~h}$ at $120^{\circ} \mathrm{C}$. After taking it out and cooling to room temperature, the surface of the plate was manually uniformly coated with high-toughness resin by using a brush with coating weight of $0.5 \mathrm{~kg} / \mathrm{m}^{2}$, and fiber cloth was immediately laid at the same time. After that, high- toughness resin was smeared on the surface of the fiber cloth again with coating weight of $0.5 \mathrm{~kg} / \mathrm{m}^{2}$, so as to ensure that the fiber cloth was fully infiltrated in the resin layer. The processes of specimen preparation are shown in Figure 5.

After being cured for $16 \mathrm{~h}$ at $23^{\circ} \mathrm{C}$, the test plate was cut into prismatic beam specimens with dimensions of $240 \pm 2 \mathrm{~mm} \times 30 \pm 2 \mathrm{~mm} \times 35 \pm 2 \mathrm{~mm}$ by using a rock cutting machine. After that, by referring to EN 12697-24-2018, the bending test was conducted on the specimens of the fiber clothreinforced epoxy resin-modified asphalt mixture by using the three-point beam ( $3 \mathrm{~PB})$ bending test. The test schematic is shown in Figure 6. By placing one side of fiber resin cloth on the bottom, the maximum bending strength, the maximum fracture strain, and bending stiffness modulus were measured. The test was carried out at room temperature $\left(15^{\circ} \mathrm{C}\right)$ and low temperature $\left(-10^{\circ} \mathrm{C}\right)$ at loading rate of $50 \mathrm{~mm} / \mathrm{min}$.

At present, there are still no specific test methods for evaluating the fatigue resistance of overlay of the fiberreinforced thin resin. Considering this, the research designed a fatigue test on plates under cyclic loading based on the rutting test, to assess the fatigue resistance of the plate. The test schematic is shown in Figure 7.

The test plates were prepared in the following steps, and the processes of specimen preparation are shown in Figure 8.

(1) A rutting plate of epoxy asphalt concrete measuring $30 \mathrm{~cm}$ long, $30 \mathrm{~cm}$ wide, and $2.5 \mathrm{~cm}$ thick was molded at first. Then, by using a stone cutting machine, the plate was cut into three plates with the dimensions of $30 \mathrm{~cm} \times 10 \mathrm{~cm} \times 2.5 \mathrm{~cm}$ (length $\times$ width $\times$ thickness), which were then halved to two plates measuring $30 \mathrm{~cm}$ long, $5 \mathrm{~cm}$ wide, and $2.5 \mathrm{~cm}$ thick.

(2) RPF high-toughness epoxy resin was used to bond the halved specimens into a test plate with the dimensions of $30 \mathrm{~cm} \times 10 \mathrm{~cm} \times 2.5 \mathrm{~cm} \quad$ (length $\times$ width $\times$ thickness), which was then put in the oven to be cured at $60^{\circ} \mathrm{C}$ for $16 \mathrm{~h}$.

(3) High-toughness resin was uniformly coated on the surface of the test plate, on which different types of fiber cloth were immediately laid. Then, hightoughness resin was smeared on the surface of the fiber cloth again after the fiber cloth was fully infiltrated in the bottom resin layer and interlaminar bubbles were removed. Then, the plate was placed in the oven to be cured for $16 \mathrm{~h}$ at $60^{\circ} \mathrm{C}$ again.

(4) After putting the cured plate in the rutting test box for $5 \mathrm{~h}$, metallic supports were placed under two sides of the plate to lift the plate by $20 \mathrm{~cm}$. Then, the fatigue test under wheel rolling was conducted. The loading wheel rolled back and forth along the direction perpendicular to the joint of the plate at the 
TABLE 3: Requirements of technical indexes of fiber cloth.

\begin{tabular}{lcccc}
\hline Fiber & Weight $\left(\mathrm{g} / \mathrm{m}^{2}\right)$ & Tensile strength $(\mathrm{MPa})$ & Tensile elastic modulus $(\mathrm{MPa})$ & Elongation $(\%)$ \\
\hline CF & 300 & $\geq 3400$ & $\geq 2.4 \times 10^{5}$ & $\geq 1.6$ \\
GF & 450 & $\geq 1500$ & $\geq 0.72 \times 10^{5}$ & $\geq 2.8$ \\
BF & 300 & $\geq 2200$ & $\geq 1.04 \times 10^{5}$ & $\geq 1.6$ \\
\hline
\end{tabular}

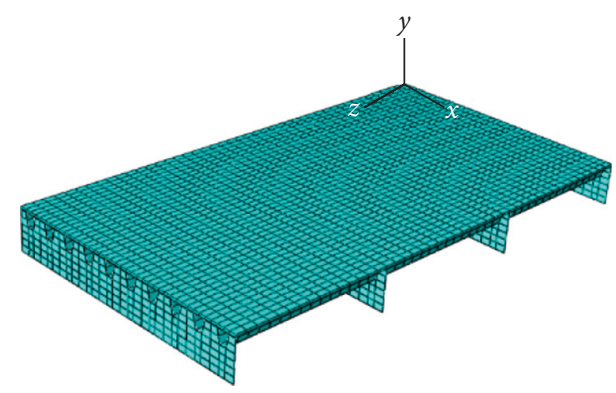

Figure 3: Structural model of steel bridge deck pavement.

speed of 42 times per minute at 60 and $75^{\circ} \mathrm{C}$. The wheel load used was $0.7 \pm 0.05 \mathrm{MPa}$. The processes of fatigue test are shown in Figure 9.

\section{Results and Discussion}

3.1. Theoretical Measurement. Based on the classical theory of fiber composites, it is considered that the single-layer fiber cloth in the fiber-reinforced resin composites studied in this research is continuously and uniformly arranged in the resin matrix and is firmly bonded to the resin matrix. It is assumed that fiber, resin matrix, and fiber cloth-reinforced resin composites have the same tensile strain. Under vertical loading force, the resin matrix completely transfers tensile force $F$ to fiber through the interface, and the simplified model is displayed in Figure 10.

According to the balance of forces, the following formulas are obtained:

$$
\begin{aligned}
F & =F_{\mathrm{f}}+F_{\mathrm{m}}=\sigma_{\mathrm{f}} \cdot A_{\mathrm{f}}+\sigma_{\mathrm{m}} \cdot A_{\mathrm{m}}, \\
A_{\mathrm{c}} & =A_{\mathrm{f}}+A_{\mathrm{m}}, \\
V_{\mathrm{f}} & =\frac{A_{\mathrm{f}}}{A_{\mathrm{c}}} \\
V_{\mathrm{m}} & =\frac{A_{\mathrm{f}}}{A_{\mathrm{c}}} \\
V_{\mathrm{f}}+V_{\mathrm{m}} & =1,
\end{aligned}
$$

where $A_{\mathrm{f}}, A_{\mathrm{m}}$, and $A_{\mathrm{c}}$ represent the cross-sectional areas of fiber, resin matrix, and fiber cloth-reinforced resin composites, respectively; $V_{\mathrm{f}}$ and $V_{\mathrm{m}}$ indicate the volume fractions of fiber and resin matrix, respectively. Moreover, $\sigma_{\mathrm{f}}$ and $\sigma_{\mathrm{m}}$ denote the forces applied on fiber and resin matrix, so the average tensile stress on fiber cloth-reinforced composites is shown as follows:

$$
\sigma_{\mathrm{cL}}=\frac{F}{A_{\mathrm{c}}}=\frac{\left(\sigma_{\mathrm{f}} \cdot A_{\mathrm{f}}+\sigma_{\mathrm{m}} \cdot A\right)}{A_{\mathrm{c}}}=\sigma_{\mathrm{f}} \cdot V_{\mathrm{f}}+\sigma_{\mathrm{m}} \cdot V_{\mathrm{m}} \text {. }
$$

In the fiber cloth-reinforced thin resin overlay, the matrix is resin. When fiber cloth and resin matrix are within the range of elastic deformation, the following formula is obtained in accordance with Hooke's law:

$$
\begin{gathered}
\sigma_{\mathrm{f}}=E_{\mathrm{f}} \cdot \varepsilon_{\mathrm{f}}, \\
\sigma_{\mathrm{m}}=E_{\mathrm{m}} \cdot \varepsilon_{\mathrm{m}}, \\
\sigma_{\mathrm{cL}}=E_{\mathrm{cL}} \cdot \varepsilon_{\mathrm{cL}},
\end{gathered}
$$

where $\varepsilon_{\mathrm{f}}, \varepsilon_{\mathrm{m}}$, and $\varepsilon_{\mathrm{cL}}$ indicate the longitudinal strains of fiber, resin matrix, and fiber cloth-reinforced resin composites, respectively; $E_{\mathrm{f}}, E_{\mathrm{m}}$, and $E_{\mathrm{cL}}$ represent the elastic moduli of fiber, resin matrix, and composites, respectively. Based on the isostrain assumption $\varepsilon_{\mathrm{f}}=\varepsilon_{\mathrm{m}}=\varepsilon_{\mathrm{cL}}$, the expression of longitudinal elastic modulus of unidirectional continuous fiber-reinforced composites, that is, the rule of the mixture is demonstrated as follows:

$$
E_{\mathrm{cL}}=E_{\mathrm{f}} \cdot V_{\mathrm{f}}+E_{\mathrm{m}} \cdot V_{\mathrm{m}}=E_{\mathrm{f}} \cdot V_{\mathrm{f}}+E_{\mathrm{m}} \cdot\left(1-V_{\mathrm{f}}\right) .
$$

Elastic moduli of CF, BF, and GF are 230, 104, and $72 \mathrm{GPa}$, respectively, and modulus of the resin matrix is $0.04 \mathrm{GPa}$. According to formula (4), the relationship between modulus of fiber-reinforced resin composites and fiber content can be obtained as shown in Figure 11. In the experiment, resin content is $1 \mathrm{~kg} / \mathrm{m}^{2}$, and weight of fiber is demonstrated in Table 3. In accordance with the ratio of weights of fiber to resin, $\mathrm{CF}$ and $\mathrm{BF}$ contents are $30 \%$ and GF content is $45 \%$. Furthermore, through theoretical calculation, moduli of CF-, BF-, and GF-reinforced resin composites are $69.03,31.23$, and $32.42 \mathrm{GPa}$, respectively.

Based on formulas (3) and (4), the following formula is obtained:

$$
\sigma_{\mathrm{cL}}=E_{\mathrm{f}} \cdot \varepsilon_{\mathrm{f}} \cdot V_{\mathrm{f}}+E_{\mathrm{m}} \cdot \varepsilon_{\mathrm{m}} \cdot\left(1-V_{\mathrm{f}}\right) .
$$

The ratio of load of fiber to resin matrix is presented as follows:

$$
\frac{F_{\mathrm{f}}}{F_{\mathrm{m}}}=\frac{E_{\mathrm{f}} \cdot \varepsilon_{\mathrm{f}} \cdot V_{\mathrm{f}}}{\left[E_{\mathrm{m}} \cdot \varepsilon_{\mathrm{m}} \cdot\left(1-V_{\mathrm{f}}\right)\right]}=\frac{E_{\mathrm{f}} \cdot V_{\mathrm{f}}}{\left[E_{\mathrm{m}} \cdot\left(1-V_{\mathrm{f}}\right)\right]} .
$$

In accordance with formula (6), when volume content $V_{\mathrm{f}}$ of fiber is certain, the larger the ratio of $E_{\mathrm{f}} / E_{\mathrm{m}}$, the more the load the fiber bears and the stronger the reinforcing effects are. In theory, because tensile elastic modulus (Table 1) of CF is higher than those of GF and BF, the effects of CF in improving bending and tensile resistance of the composite resin overlay and overall structure of the mixture are the best.

Similarly, $E_{\mathrm{m}}^{\prime}, E_{\mathrm{f}}^{\prime}$, and $E_{\mathrm{cL}}^{\prime}$ represent the elastic moduli of the matrix of EAM, fiber, and composite structure, respectively; $V_{\mathrm{m}}^{\prime}$ and $V_{\mathrm{f}}^{\prime}$ indicate the volume fractions of the matrix of EAM and fiber, respectively. Based on bending test of the mixture, tensile elastic modulus of the matrix of EAM in the linear elastic stage is $1,063 \mathrm{MPa}$, and theoretical moduli of CF-, BF-, and GF-reinforced resin composites are 
TABle 4: Model parameters in finite element simulation.

\begin{tabular}{|c|c|c|c|c|c|}
\hline Structural layer & Length $(\mathrm{m})(Z)$ & Width $(\mathrm{m})(X)$ & Thickness $(\mathrm{m})(Y)$ & Elastic modulus (MPa) & Poisson's ratio \\
\hline Thin overlay & 11.25 & 6 & 0.005 & - & 0.25 \\
\hline Original pavement layer & 11.25 & 6 & 0.055 & 2000 & 0.25 \\
\hline Steel bridge deck & $3.75 \times 3$ & 6 & 0.014 & 210000 & 0.3 \\
\hline Transverse diaphragm plate & 0.01 & 6 & 0.84 & 210000 & 0.3 \\
\hline U-shaped rib & 11.25 & 0.006 & 0.28 & 210000 & 0.3 \\
\hline
\end{tabular}

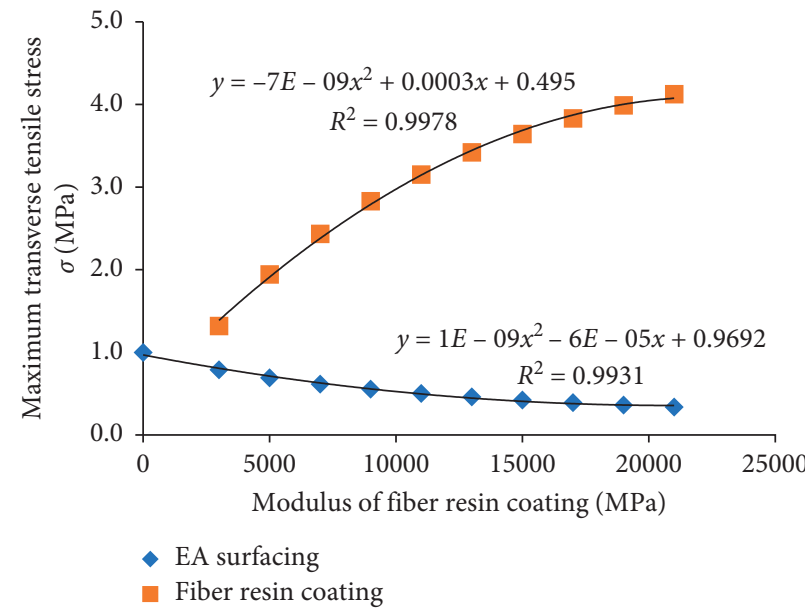

(a)

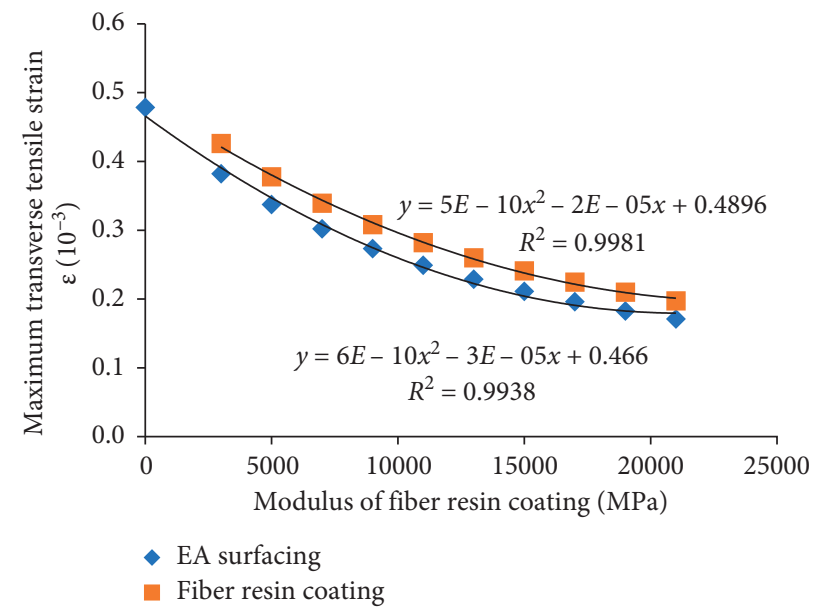

(b)

Figure 4: Change laws of the maximum tensile stress and strain of the pavement layer with modulus of the thin overlay.

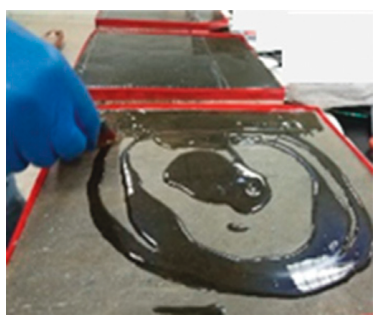

(a)

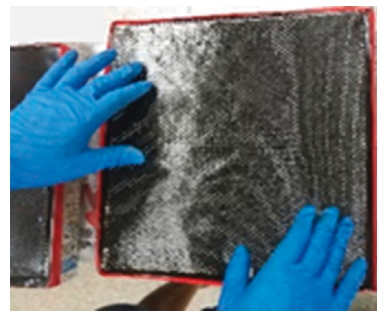

(b)

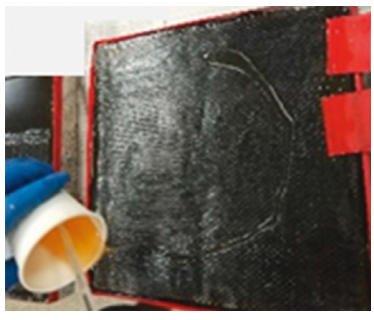

(c)

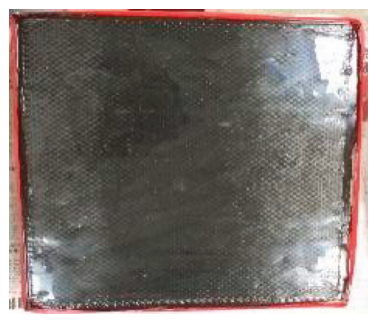

(d)

FigURE 5: Specimen preparation of fiber-reinforced resin composite overlay: (a) blade coating resin on the bottom; (b) laying fiber cloth; (c) brush coating resin on the surface; (d) curing.

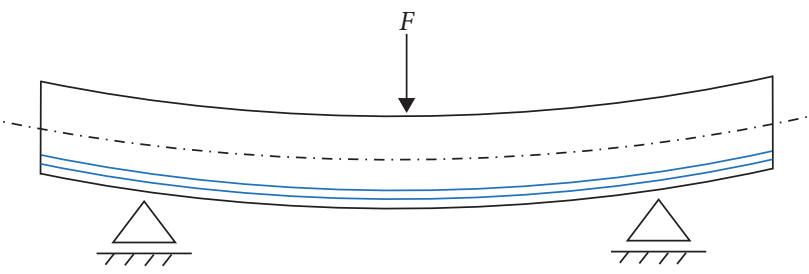

Figure 6: Tensile and bending test of the fiber overlay.

$69,030,31,230$, and 32,420 MPa, respectively. In accordance with formula (4), theoretical values of tensile elastic moduli of the fiber-reinforced composite structure are shown in Table 5.

\subsection{Evaluation of Cracking Resistance}

3.2.1. Test at Room Temperature. The bending test results at room temperature are shown in Figure 12. The bending

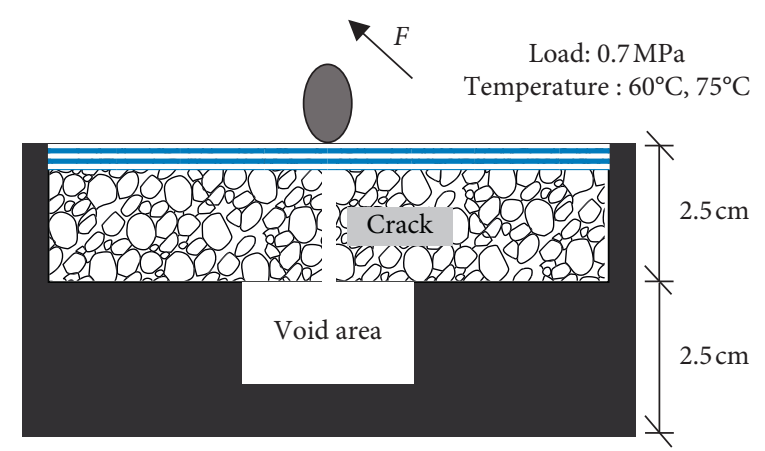

FIGURE 7: Schematic diagram of fatigue test on plates based on rutting.

strength of the EAM beam (blank specimen) is 7.29 MPa at room temperature of $15^{\circ} \mathrm{C}$, and the maximum bending strain and bending stiffness in failure are $10,876 \mu \varepsilon$ and 


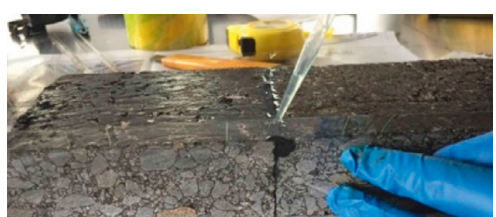

(a)

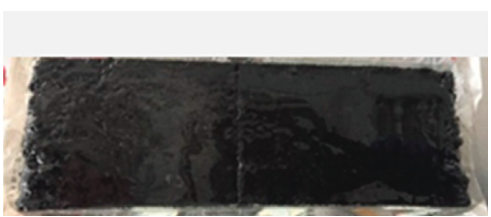

(b)

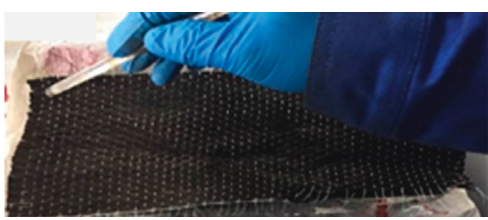

(c)

Figure 8: Preparation process of the test plate for the fatigue test. (a) Bonding using the high-toughness resin. (b) Smearing the hightoughness resin. (c) Laying CF cloth.

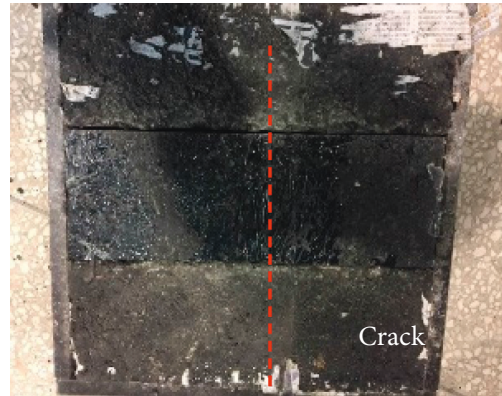

(a)

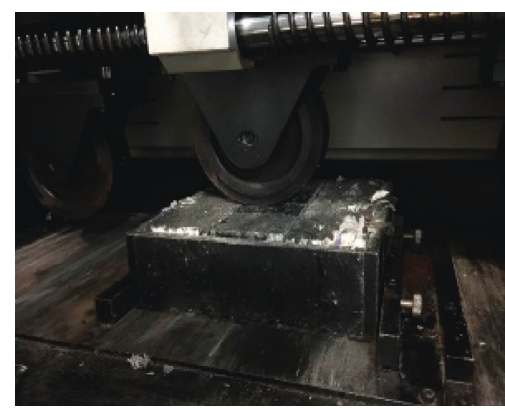

(b)

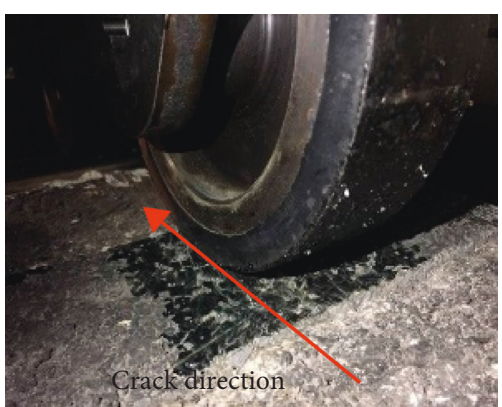

(c)

Figure 9: Fatigue test on the plate.

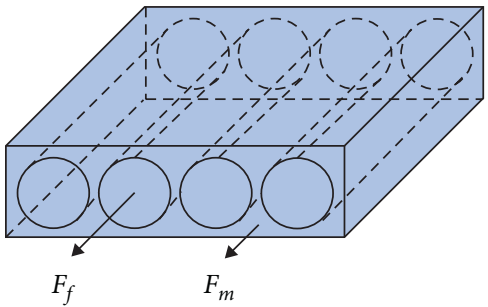

(a)

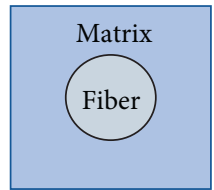

(b)

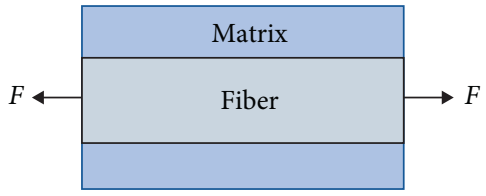

(c)

Figure 10: Simplified model of unidirectional continuous composites.

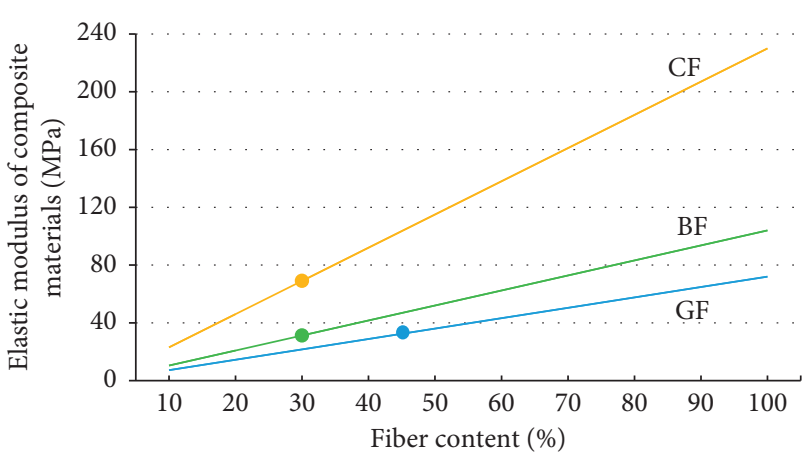

Figure 11: Moduli and fiber contents of unidirectional continuous composites.

$670 \mathrm{MPa}$, respectively. After fiber reinforcement, bending strength, maximum bending strain, and bending stiffness of the EAM are improved to some extent. At room temperature of $15^{\circ} \mathrm{C}$, the reinforcement amplitude of CF is the highest and bending strength and the maximum bending strain can be improved to $99.62 \mathrm{MPa}$ and
TABLE 5: Tensile elastic moduli of the composite structure through theoretical calculation at room temperature.

\begin{tabular}{lcc}
\hline No. & Material & Tensile elastic modulus (MPa) \\
\hline 1 & EAM beam & 1063 \\
2 & CF-reinforced beam & 4733 \\
3 & BF-reinforced beam & 2692 \\
4 & GF-reinforced beam & 2756 \\
\hline
\end{tabular}

$50,393 \mu \varepsilon$. Moreover, bending stiffness in failure can be increased to $1,778 \mathrm{MPa}$. The reinforcement amplitudes of GF and BF are basically the same and their bending strengths are 41.2 and $42.7 \mathrm{MPa}$. Furthermore, the maximum bending strains are 28,760 and $32,458 \mu \varepsilon$ and bending stiffness in failure is 1,435 and $1,308 \mathrm{MPa}$, respectively.

As shown in Figure 13, at room temperature of $15^{\circ} \mathrm{C}$, with constant increase of load, bending deflections of the beams linearly rise and shows a good linear elastic trend. The CF-reinforced beam has the highest bending stiffness, followed by GF- and BF-reinforced ones, which all show the 


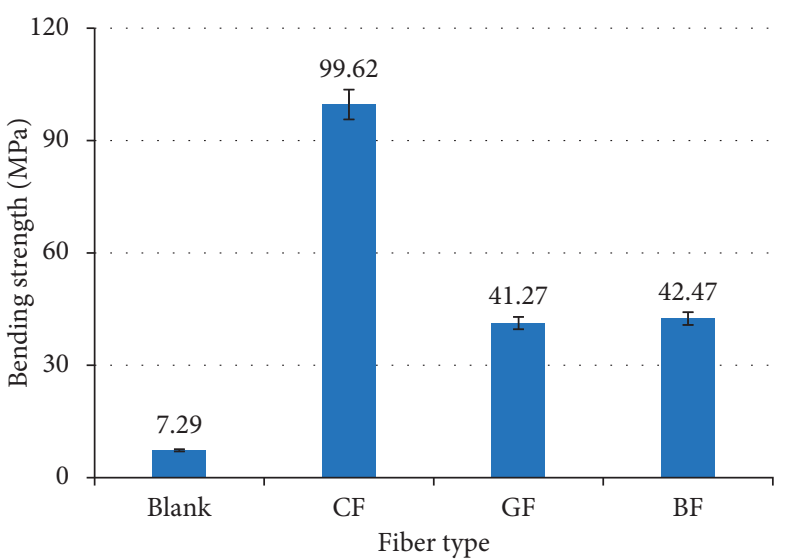

(a)

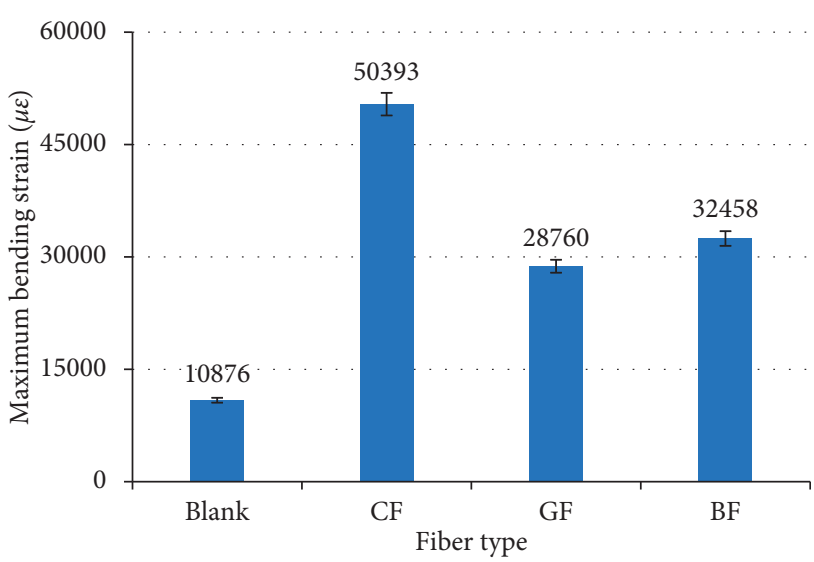

(b)

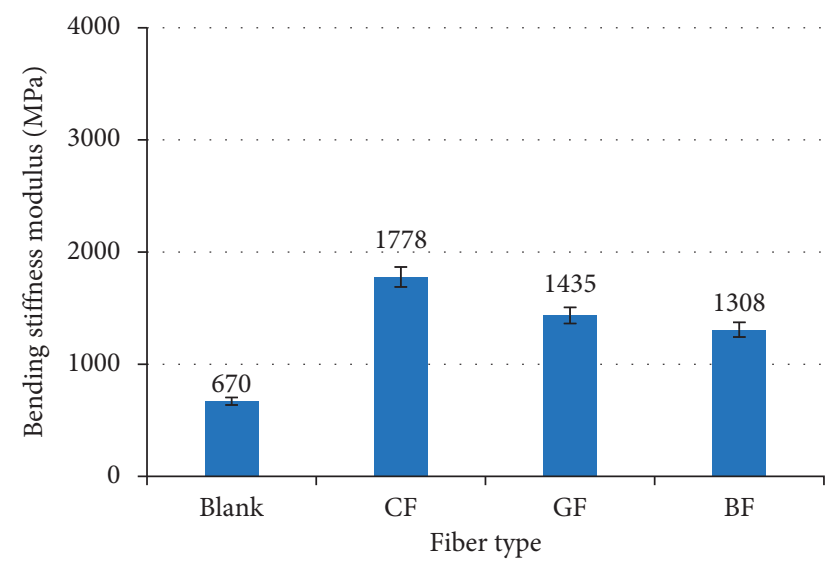

(c)

Figure 12: Bending test results at room temperature: (a) bending strength at $15^{\circ} \mathrm{C}$; (b) the maximum bending strain at $15^{\circ} \mathrm{C}$; (c) bending stiffness modulus in failure at $15^{\circ} \mathrm{C}$.

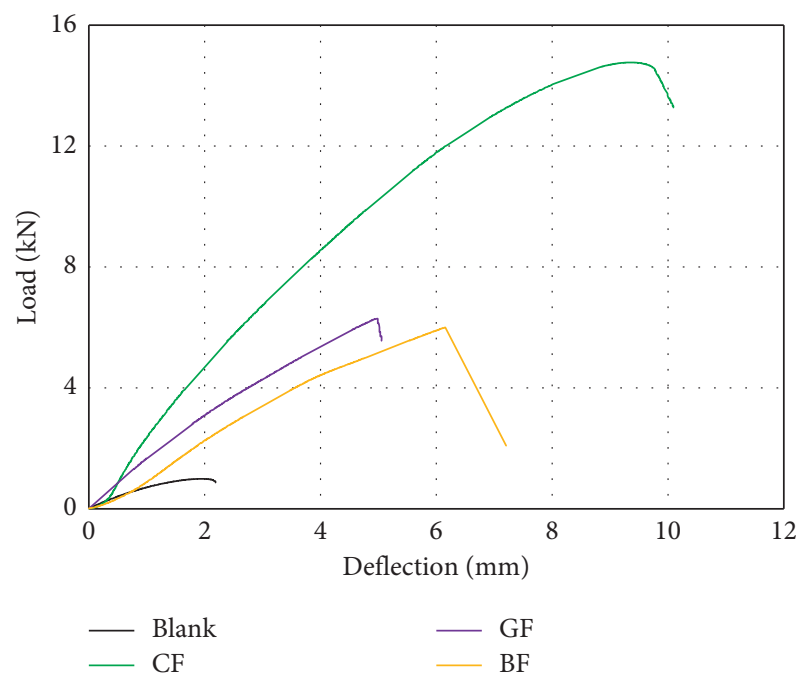

FIgURE 13: Load-deflection curves at $15^{\circ} \mathrm{C}$.

typical brittle failure. This law well corresponds to tensile strength and modulus of fiber materials, that is, the higher the tensile strength and elastic modulus of fiber materials for reinforcement, the better the reinforcing effects.
Failure and fracture of the specimens at room temperature of $15^{\circ} \mathrm{C}$ are shown in Figure 14. The EAM beam (blank specimen), GF-reinforced beam, and BF-reinforced beam all show fracture failure of normal section. The specimen of CFreinforced beam presents obvious failure phenomenon that the CF-reinforced resin and the epoxy asphalt beam are separated at the bond interface. This indicates that strength and tensile elastic modulus of the CF-reinforced resin composite are much larger than those of the EAM beam, and displacements of them under the same load are inconsistent. With the increase of bending and tensile load, relative slippage occurs on the interface of the CF-reinforced beam, finally resulting in delaminating failure.

3.2.2. Test at Low Temperature. The bending test results at low temperature of $-10^{\circ} \mathrm{C}$ are shown in Figure 15; in comparison with the room temperature of $15^{\circ} \mathrm{C}$, bending strength of the EAM beam (blank specimen) increases to 15.98 MPa with the decrease of temperature. Moreover, the maximum bending strain reduces to $5,865 \mu \varepsilon$ and bending stiffness in failure rises to $2,724 \mathrm{MPa}$. After fiber reinforcement, bending strength and the maximum bending strain of EAM increase to some extent. 


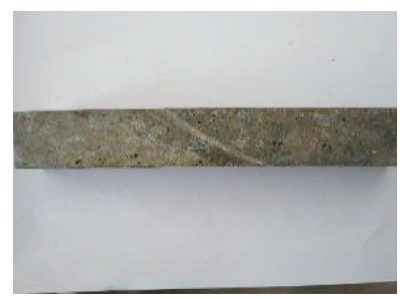

(a)

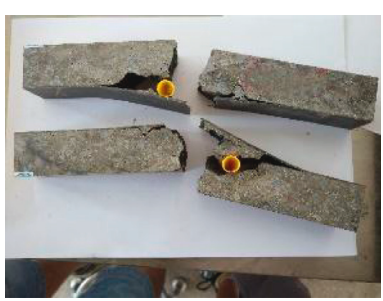

(b)

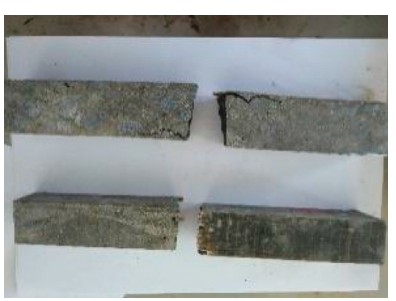

(c)

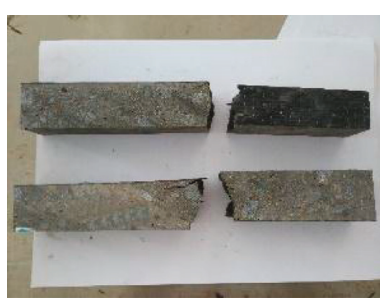

(d)

FIGURE 14: Fracturing behaviors of beam specimens of resin composite overlay reinforced with different fibers at $15^{\circ} \mathrm{C}$. (a) Blank. (b) CF. (c) GF. (d) BF.

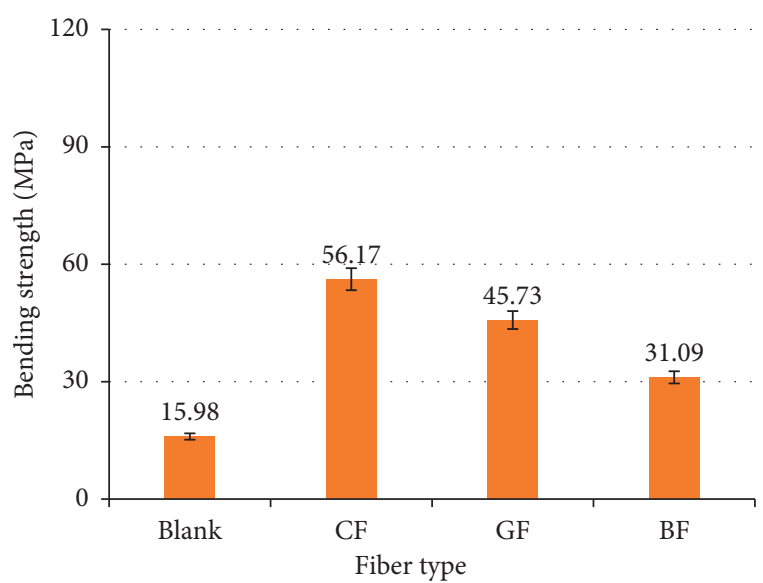

(a)

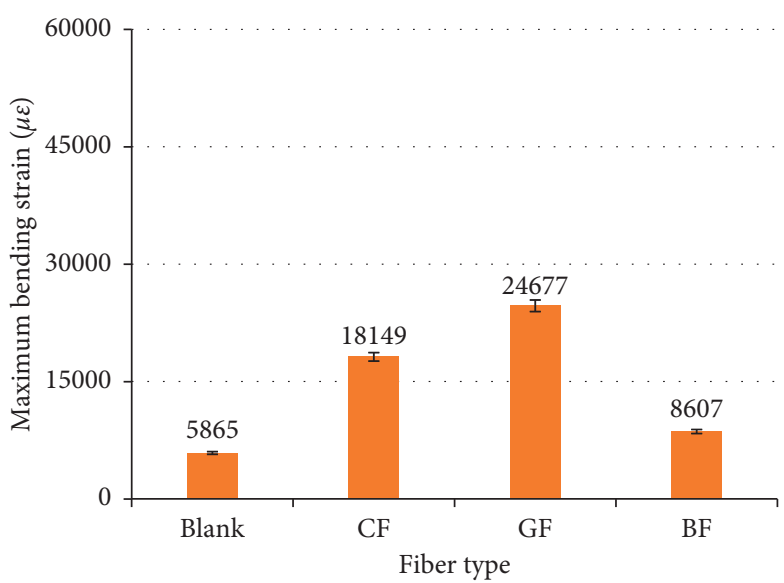

(b)

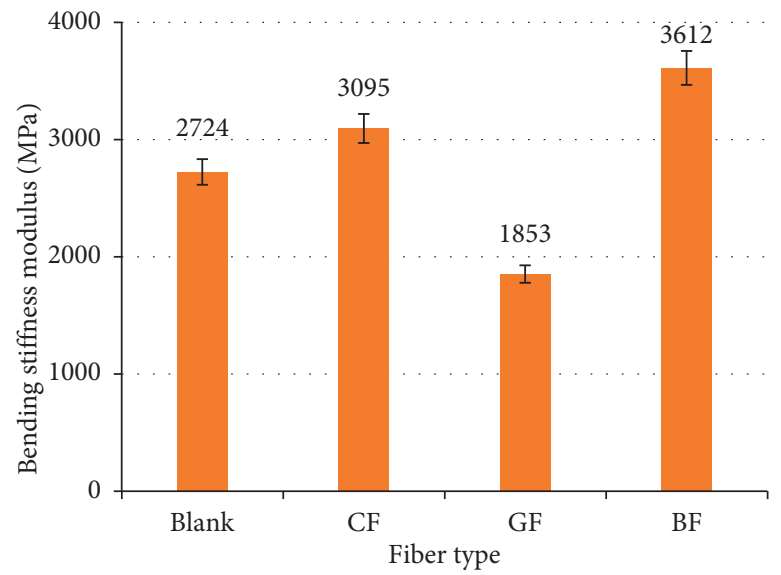

(c)

Figure 15: Bending test results at low temperature. (a) Bending and tensile strength at $-10^{\circ} \mathrm{C}$; (b) the maximum bending and tensile strain at $-10^{\circ} \mathrm{C}$; (c) bending stiffness modulus at $-10^{\circ} \mathrm{C}$.

At low temperature of $-10^{\circ} \mathrm{C}$, reinforcing effects of $\mathrm{CF}$ are optimal. Bending strength and the maximum bending strain of the CF-reinforced beam are $56.17 \mathrm{MPa}$ and $18,149 \mu \varepsilon$, respectively, and bending stiffness in failure is 2,724 MPa. For the BF-reinforced beam, bending strength and the maximum bending strain are $31.09 \mathrm{MPa}$ and $8,607 \mu \varepsilon$, and bending stiffness in failure is $3,612 \mathrm{MPa}$. In addition, bending strength, maximum bending strain, and bending stiffness in failure of the GF-reinforced beam are 45.73 MPa, 24,677 $\mu \varepsilon$, and 1,853 MPa, respectively.
As shown in Figure 16, at low temperature of $-10^{\circ} \mathrm{C}$, as load constantly rises, bending deflections of the beams linearly increase at first. The typical brittle failure is still found on the EAM beam (blank specimen). After fiber reinforcement, when load rises to a certain degree, there is a certain yield phenomenon in the late stage, gradually changing from the initial elastic deformation to plastic deformation until the mixture is finally fractured.

The reason for yield phenomenon at low temperature is generally that shear failure is likely to appear to the materials 


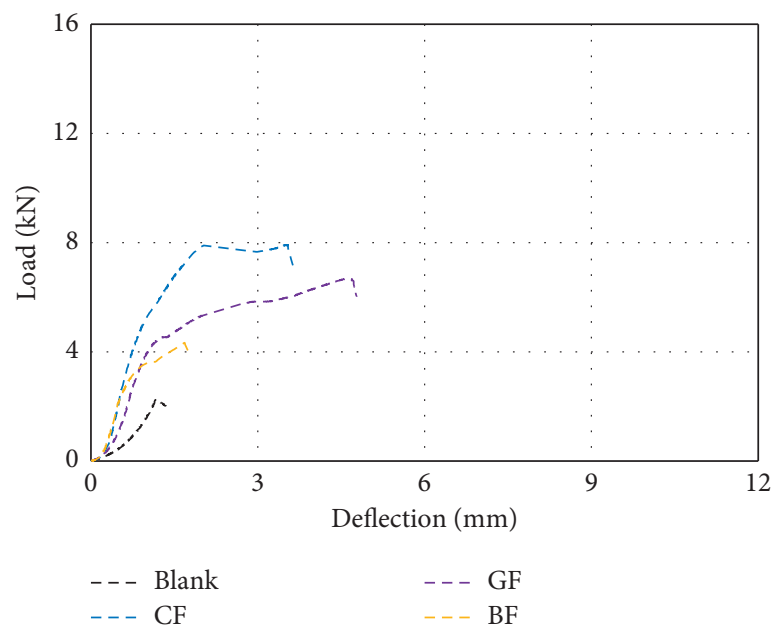

Figure 16: Load-deflection curves at $-10^{\circ} \mathrm{C}$.

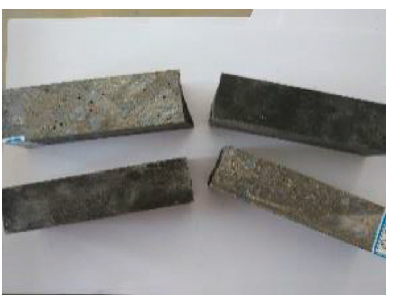

(a)

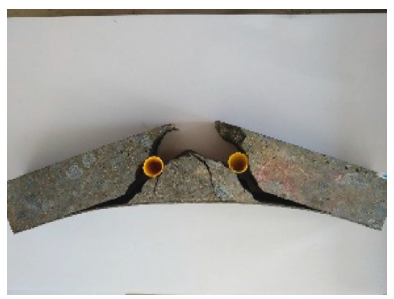

(b)

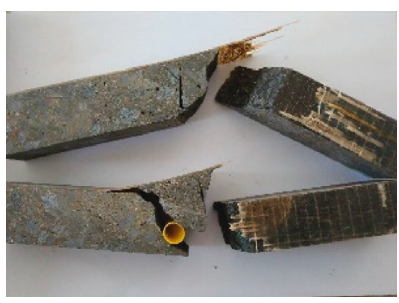

(c)

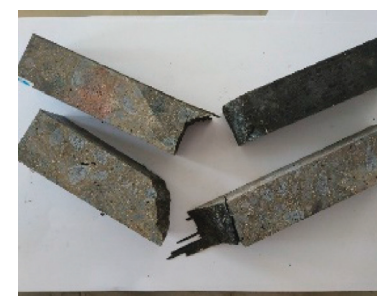

(d)

FIGURE 17: Fracturing behaviors of the beam specimens of resin composite overlays reinforced with different fibers at $-10^{\circ} \mathrm{C}$. (a) Blank. (b) CF. (c) GF. (d) BF.

under bending and tensile forces. The fracture surface of the specimens at low temperature of $-10^{\circ} \mathrm{C}$ is further verified, as shown in Figure 17. The EAM beam (blank specimen) still shows brittle fracture failure. For CF-, GF-, and BF-reinforced beams, the fracture surface shows an angle of $45^{\circ}$ with load, indicating that tensile strength of the normal section of the materials is very high owing to modulus of fiber largely increasing at low temperature. With the rise of bending and tensile load, shear stress of the oblique section of the materials exceeds the maximum strength, so essentially the materials show shear failure.

\subsubsection{Comparison of Room-Temperature and Low-Temper-} ature Performances. By analyzing results of different specimens at room temperature and low temperature as shown in Figure 18, the following conclusions are made:

(1) With the reduction of temperature, obvious brittle phenomenon is found on the EAM beam (blank specimen) and bending stiffness in failure rises from 670 to $2,724 \mathrm{MPa}$, with increase amplitude of $300 \%$. Bending strength increases from 7.29 to $15.98 \mathrm{MPa}$, while the maximum bending strain decreases from 10,876 to $5,865 \mu \varepsilon$.

(2) Change of performances of the organic CF-reinforced beam is sensitive to temperature, and bending stiffness in failure increases by $74 \%$ compared with that at room temperature. Bending strength reduces by $44 \%$ from
99.62 to $56.17 \mathrm{MPa}$ and the maximum bending strain decreases to $18,149 \mu \varepsilon$ with amplitude of $64 \%$.

(3) In comparison with room temperature, bending stiffness of the BF-reinforced beam increases by $176 \%$, while bending strength decreases by $26 \%$. Furthermore, the maximum bending strain reduces by $73 \%$ from 32,458 to $8,607 \mu \varepsilon$.

(4) For inorganic nonmetal GF-reinforced beam, the change of performance is least sensitive. Bending stiffness rises by $29 \%$ compared with that at room temperature, while bending strength increases from 41.27 to $45.73 \mathrm{MPa}$, with amplitude of $10 \%$. In addition, bending strain reduces by $14 \%$ from 28,670 to $24,677 \mu \varepsilon$.

3.3. Evaluation of Fatigue Performance. The results of fatigue tests on the plates are shown in Table 6. Considering that modulus of materials always decreases and cracking resistance of structures declines at high temperatures, the research focuses on testing of fatigue and cracking resistance of the plate at high temperatures. The results of fatigue tests on the plates are consistent with those of static bending tests. The results reveal that

(1) The EAM beam (blank specimen) is fractured immediately after loading at high temperature of $60^{\circ} \mathrm{C}$, while BF-, GF-, and CF-reinforced beams are not damaged, even no cracking appearing at the joints. 


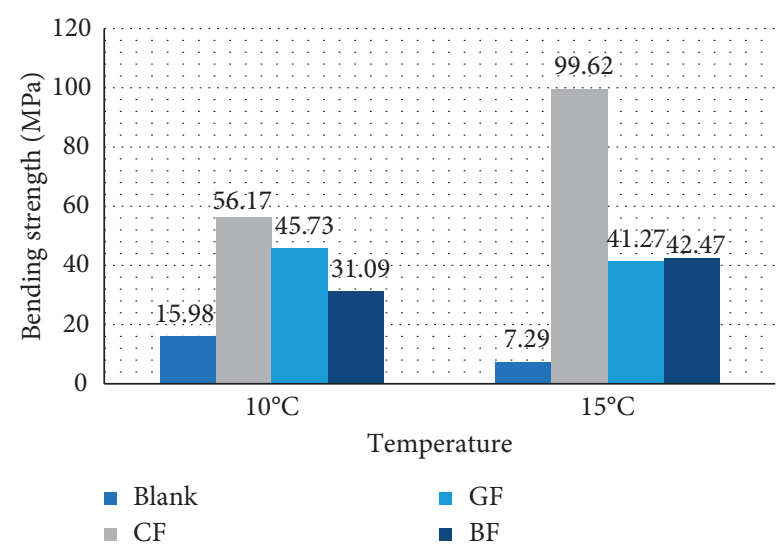

(a)

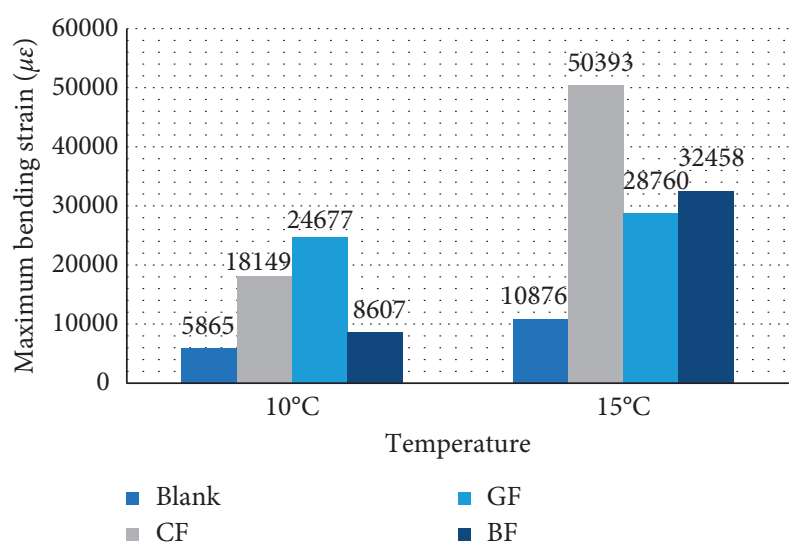

(b)

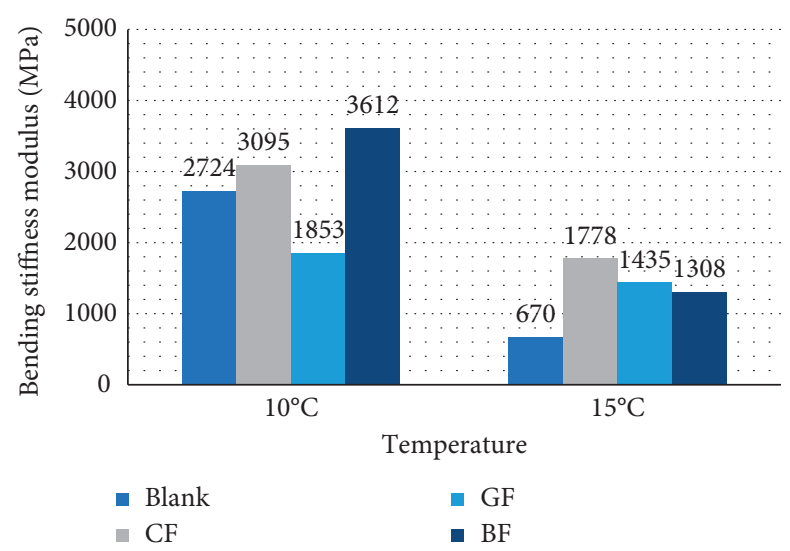

(c)

FIGURE 18: Room-temperature and low-temperature performances: (a) bending strength; (b) the maximum failure strain; (c) bending stiffness modulus in failure.

TABLE 6: Fatigue test results of composite structures under wheel rolling at 60 and $75^{\circ} \mathrm{C}$.

\begin{tabular}{|c|c|c|c|}
\hline Fiber type & Temperature $\left({ }^{\circ} \mathrm{C}\right)$ & Test time $(\mathrm{h})$ & Result \\
\hline \multirow{2}{*}{ EAM beam } & 60 & - & Fracture failure immediately after loading \\
\hline & 75 & - & Fracture failure immediately after loading \\
\hline \multirow{2}{*}{ BF-reinforced beam } & 60 & 2 & No fracture \\
\hline & 75 & 1 & No fracture and obvious bending at the midspan \\
\hline \multirow{2}{*}{ GF-reinforced beam } & 60 & 2 & No fracture \\
\hline & 75 & 1 & Cracking of the mixture \\
\hline \multirow{2}{*}{ CF-reinforced beam } & 60 & 2 & No fracture \\
\hline & 75 & 2 & No fracture \\
\hline
\end{tabular}

(2) As the temperature rises to $75^{\circ} \mathrm{C}$, fractures still occur to the EAM beam immediately after loading; the GF-reinforced beam is fractured after loading for $1 \mathrm{~h}$; the BF-reinforced beam presents certain bending after loading for $1 \mathrm{~h}$; while no cracking occurs to the CF-reinforced beam. The fatigue cracking behaviors of the specimens are shown in Figure 19.

\section{Application and Effect}

The research results have been applied in the pavement and maintenance projects of a series of steel bridge decks, including Zhenjiang-Yangzhou Yangtze River Bridge, the third Nanjing Yangtze River Bridge, and Suzhou-Nantong Bridge, which are shown in Figures 20 and 21. Double-layer epoxy asphalt of $5.5 \mathrm{~cm}$ thick was paved on these steel bridge decks. The construction technologies of the thin overlays mainly involve sandblasting and shot blasting of the original pavement (to enhance the interfacial bonding), smearing of resin, and laying of CF cloth. In addition, to improve the skid resistance, basalt gravels with grain size of $3 \sim 5 \mathrm{~mm}$ need to be spread on the surface of resin. The structure depth can be as thick as $1.2 \mathrm{~mm}$ and the frictional coefficient exceeds 60 BPN. The structural design of the application scheme is displayed in Figure 22. The research results have been applied to the bridges for at least 5 years and still present favorable effects. 


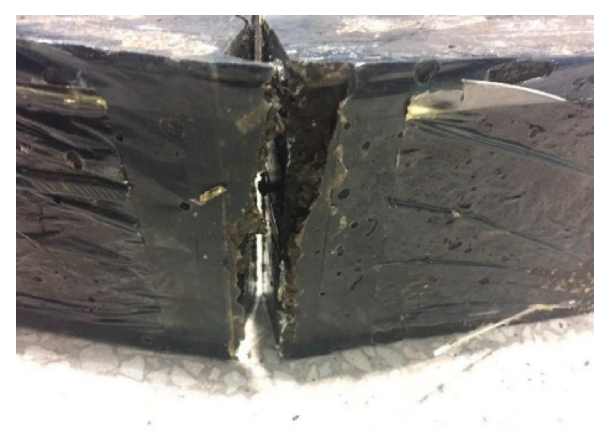

(a)

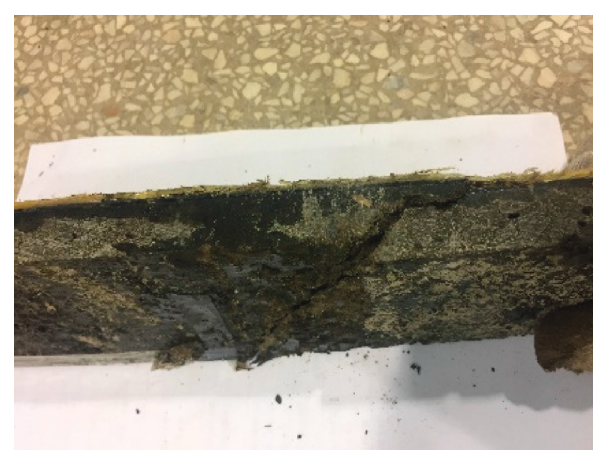

(c)

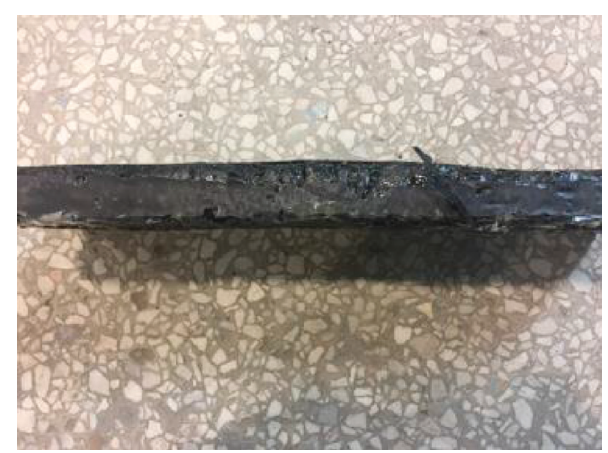

(b)

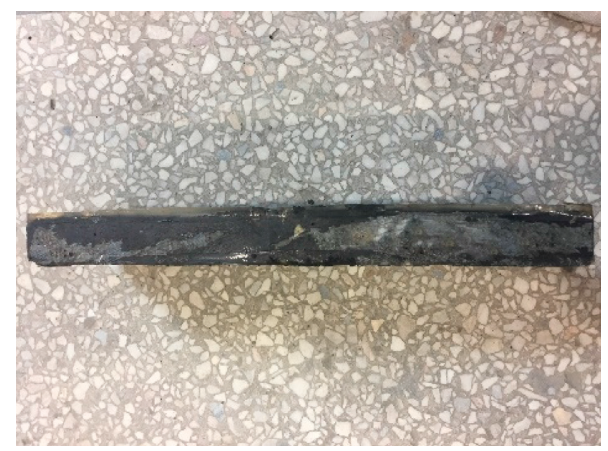

(d)

FIGURE 19: Fatigue cracking behaviors of the specimens of resin composite overlays reinforced with different fibers at $75^{\circ} \mathrm{C}$. (a) Blank. (b) BFreinforced beam. (c) GF-reinforced beam. (d) CF-reinforced beam.

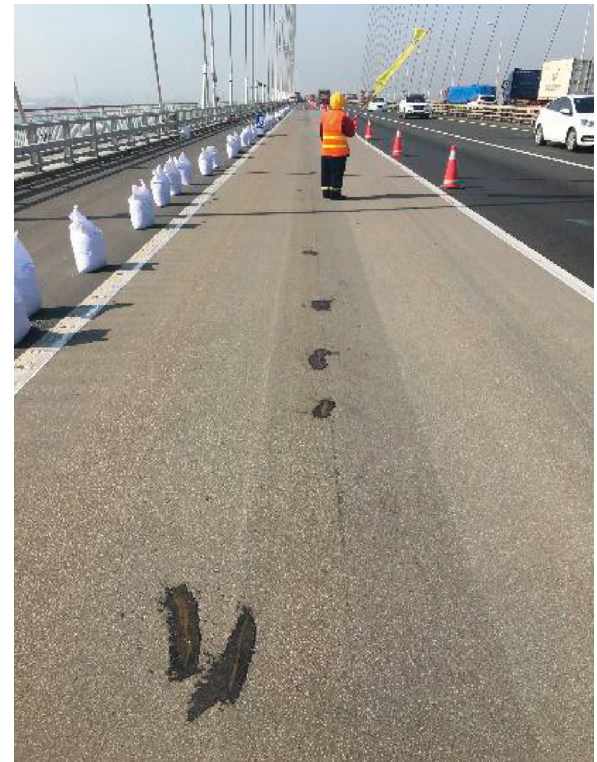

(a)

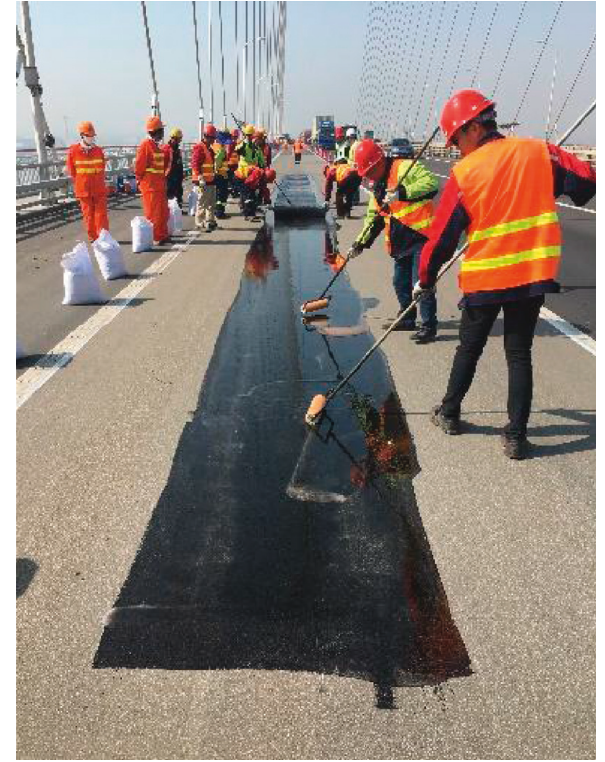

(b)

Figure 20: Continued. 


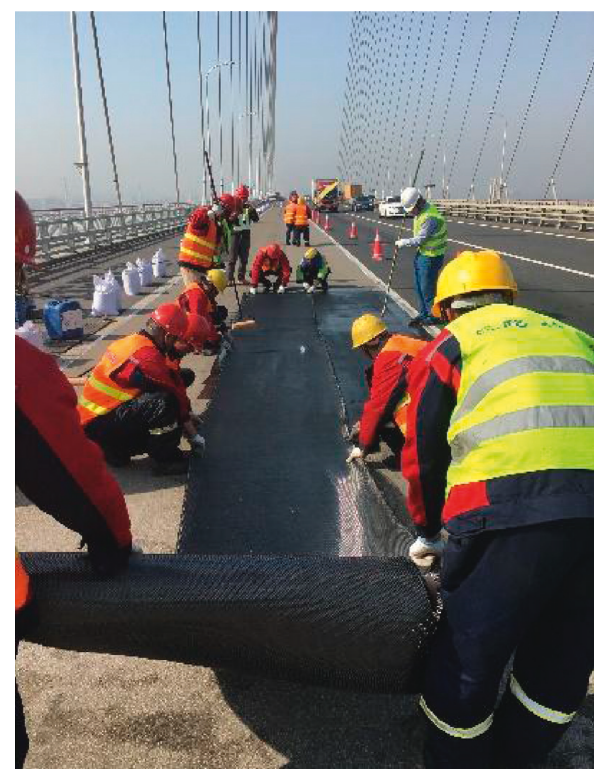

(c)

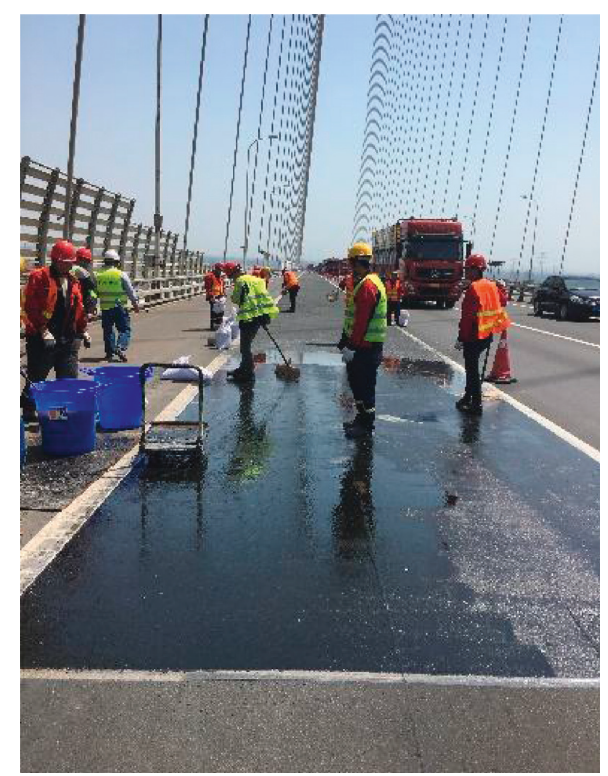

(d)

Figure 20: Construction technology of the thin overlay of fiber-reinforced resin on the Suzhou-Nantong Bridge.

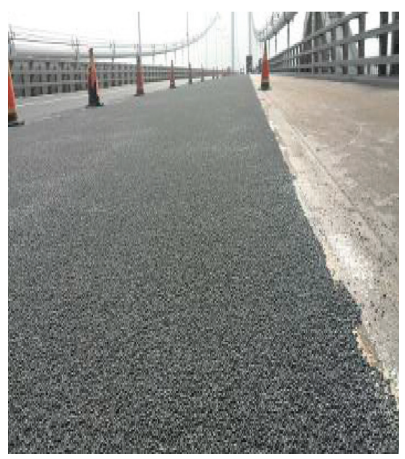

(a)

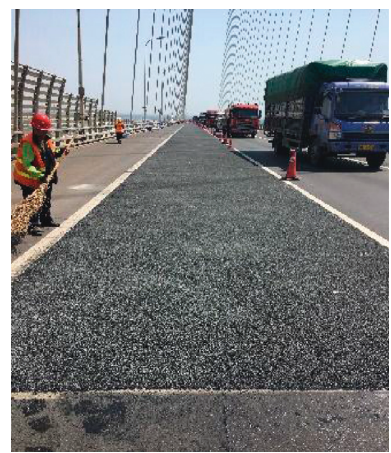

(b)

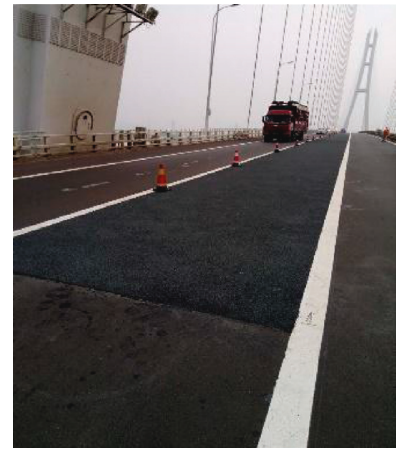

(c)

Figure 21: Effects of construction. (a) Zhenjiang-Yangzhou Yangtze River Bridge (2014). (b) The third Nanjing Yangtze River Bridge. (c) Suzhou-Nantong Bridge.

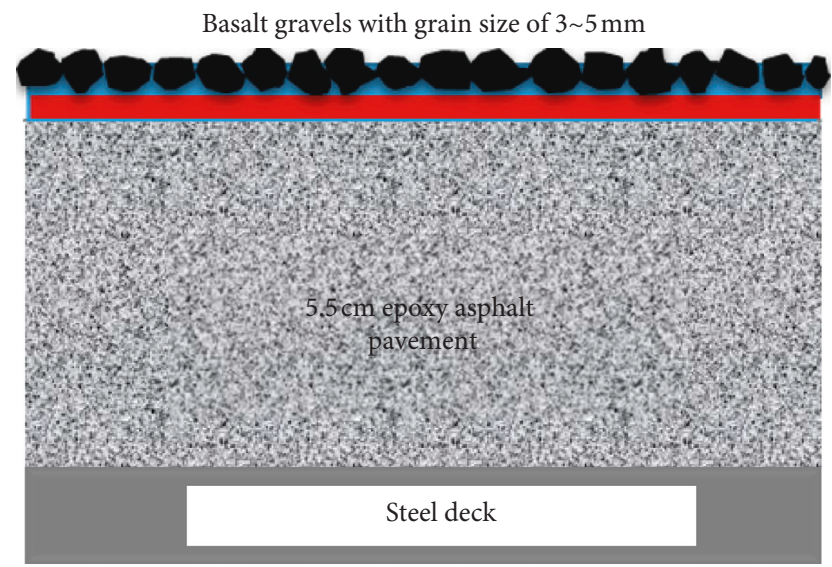

FIgURE 22: Structure of the thin overlay of fiber-reinforced resin.

\section{Conclusion}

Through beam bending test, this study mainly investigated change laws of bending and tensile performances of epoxy asphalt concrete after fiber reinforcement and analyzed bending strength and the maximum failure strain of the beams at different temperatures. Moreover, reinforcing effects of different fibers were discussed. The main conclusions are made as follows:

(1) After fiber reinforcement, bending strength, maximum failure strain, and stiffness modulus of the EAM beam are improved, which is favorable for cracking resistance in pavement. It provides a theoretical basis manifesting the engineering application value of the thin overlay of fiber-reinforced resin. 
(2) As temperature decreases, the bending and failure mode of fiber-reinforced EAM changes from brittle fracture into shear failure, accompanied with significant yield phenomenon. The result suggests that the thin overlay of fiber-reinforced resin is able to change the brittle failure of the original EAM pavement to yield failure, which makes most of the performance of the pavement materials and exerts practical significance for prolonging the service life.

(3) By comparing results of CF, GF, and BF, it is found that organic fiber is sensitive to influences of temperature, while GF is least sensitive to temperature.

(4) By performing fatigue tests on plates, it is found that compared with the original EAM pavement, the CFreinforced specimen improved the fatigue and cracking resistance at the greatest extent, particularly showing favorable effects at high temperatures.

(5) To enhance the application value in engineering, a thin overlay structure of CF-reinforced resin and gravel is designed. It can improve fatigue performance and skid resistance of the pavement. The earliest application of the design has been in service for 8 years, still showing favorable effects.

\section{Data Availability}

The data used to support the findings of this study have not been made available.

\section{Conflicts of Interest}

The authors declare that there are no conflicts of interest.

\section{Acknowledgments}

The authors would like to acknowledge the Jiangsu Natural Science Foundation (Youth Fund) (BK20180113), the Jiangsu Natural Science Foundation (Surface Project) (BK20181112), the High-Level Talent Project Funding Scheme of Jiangsu (XCL-CXTD-007), the Post-Doctoral Fund of China (2018M630559), and the Fundamental Research Nantong Metro Group Co., Ltd. for their financial support in this project.

\section{References}

[1] M. S. G. Cullimore, I. D. Flett, and J. W. Smith, "Flexure of steel bridge deck plate with asphalt surfacing," IABSE Periodical, vol. 1, pp. 58-83, 1983.

[2] T. O. Medani, "Asphalt surfacing applied to orthotropic steel bridge decks," Report 7-01-127-1, Delft University of Technology, Delft, Netherlands, 2001.

[3] V. S. Gopalaratnam, J. W. Baldwin, B. A. Hartnagel, and R. A. Rigdon, "Evaluation of wearing surface systems for orthotropic steel plate bridge decks," Report 89-2, Missouri Highway Transportation Dept, University of Missouri, Columbia, MI, USA, 1989.

[4] European Asphalt Pavement Association, Asphalt Pavements on Bridge Decks, European Asphalt Pavement Association, Brussels, Belgium, 2013.
[5] W. Huang, Z. Qian, G. Chen, and J. Yang, "Epoxy asphalt concrete paving on the deck of long-span steel bridges," Chinese Science Bulletin, vol. 48, no. 21, pp. 2391-2394, 2003.

[6] W. Huang, Z. Qian, and G. Cheng, "Application of epoxy asphalt concrete to pavement of long span steel bridge deck," Journal of Southeast University (Natural Science Edition), vol. 32, no. 5, pp. 783-787, 2002, in Chinese.

[7] Z.-D. Qian, L. I. Zhi, and C.-H. Chen, "Fracture criterion for mode I crack of epoxy asphalt concrete paving course of steel deck bridge pavement," China Journal of Highway and Transport, vol. 21, no. 5, pp. 33-38, 2008.

[8] T. J. Chen, Research on Crack Behavior of Long-Span Steel Bridge Deck Epoxy Asphalt Pavement, Southeast University, Nanjing, China, 2006.

[9] H. Zhang, Y. Pan, and C. Yin, "Research on cracking mechanism and repair techniques of epoxy asphalt on steel bridge deck pavement," in Proceedings of the 2016 TRB Annual Meeting, pp. 16-3539, Washington, DC, USA, January 2016.

[10] H. Zhang, Y. Pan, and D. Yu, "Study on the properties of rapidly repairing materials in steel bridge deck pavement based on cold-blended modified resin," Modern Transportation Technology, vol. 1, no. 12, pp. 7-8, 2005.

[11] H. Zong, Technique Research on Diseases Restoration for Epoxy Asphalt Concrete Paved on Steel Deck Bridge, Southeast University, Nanjing, China, 2005.

[12] H. Zhang, G. Shan, and Y. Pan, "Thin overlay technology for cold-blended modified resin in steel bridge deck pavement with epoxy asphalt," Transportation Science \& Technology, vol. 2, pp. 169-172, 2016.

[13] Transportation Research Board of the National Academies, "Long-Term Performance of Polymer Concrete for Bridge Decks," NCHRP SYNTHEIS 423, Transportation Research Board of the National Academies, Washington, DC, USA, 2011.

[14] Transportation Research Board of the National Academies, "Fiber additives in asphalt mixtures," NCHRP Syntheis 475, Transportation Research Board of the National Academies, Washington, DC, USA, 2015.

[15] J. Feng, Reinforcing Mechanisms and Properties of Fiber Asphalt Mixture, Southeast University, Nanjing, China, 2006.

[16] Y. Sun, M. Zhang, and L. Wang, "Analysis of viscoelastic damages of crack resistance of fiber reinforced asphalt concrete pavement," Highway, vol. 58, no. 8, pp. 174-178, 2013.

[17] B. Burks, J. Middleton, D. Armentrout, and M. Kumosa, "Effect of excessive bending on residual tensile strength of hybrid composite rods," Composite Materials Science and Technology, vol. 70, no. 10, pp. 1490-1496, 2010.

[18] C. Atas and A. Dogan, "An experimental investigation on the repeated impact response of glass/epoxy composites subjected to thermal ageing," Composites Part B: Engineering, vol. 75, pp. 127-134, 2015.

[19] M. Zhang, B. Sun, and B. Gu, "Accelerated thermal ageing of epoxy resin and 3-D carbon fiber/epoxy braided composites," Composites Part A: Applied Science and Manufacturing, vol. 85, pp. 163-171, 2016. 


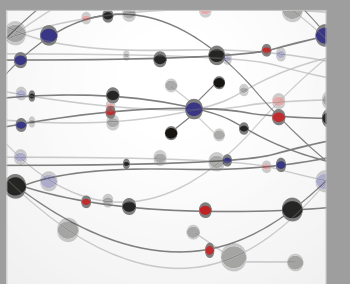

The Scientific World Journal
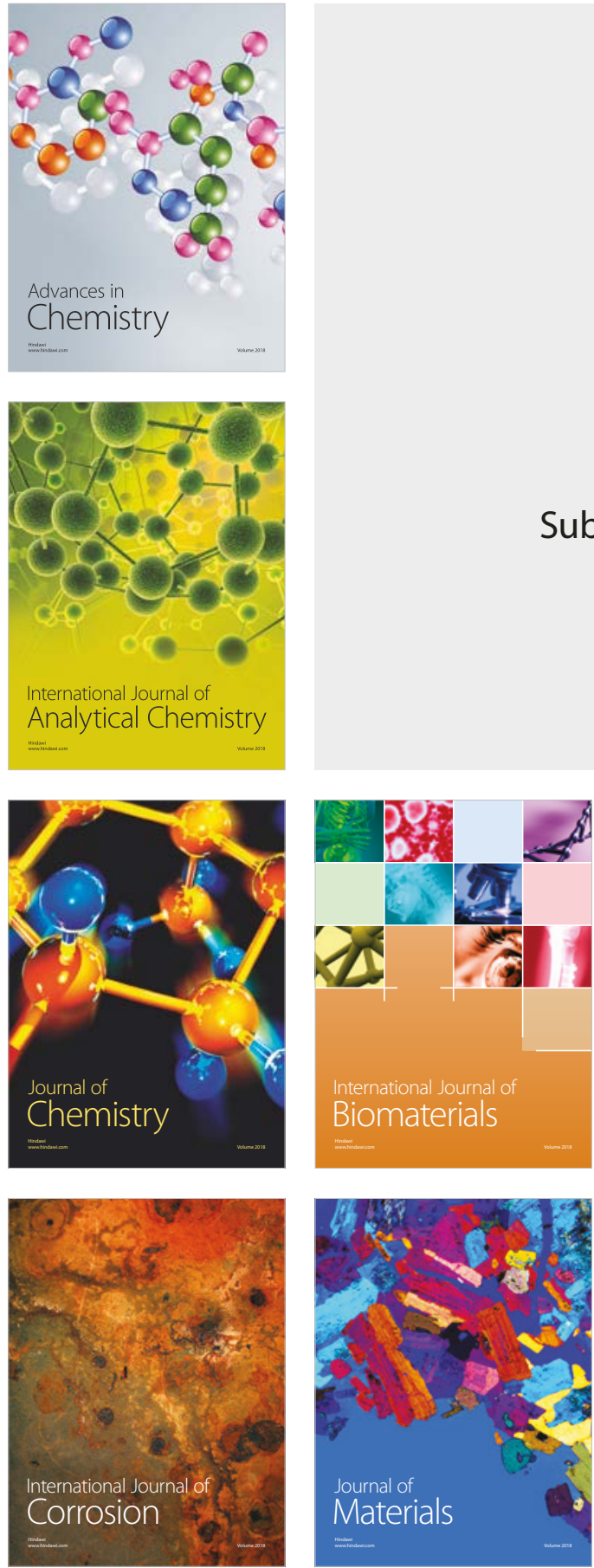

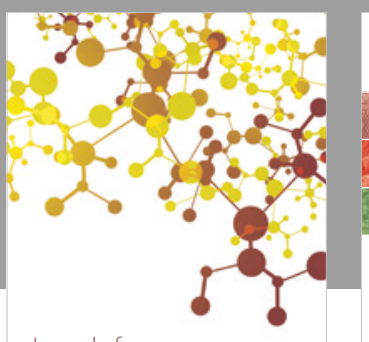

Journal of

Applied Chemistry
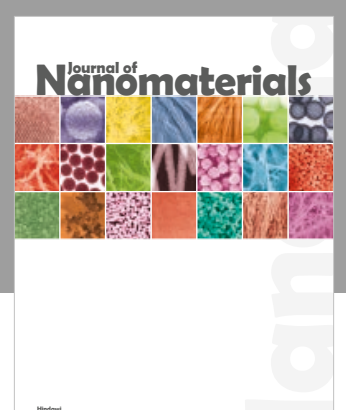

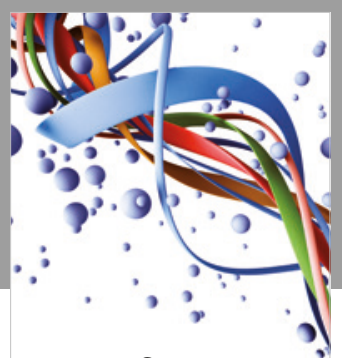

Scientifica

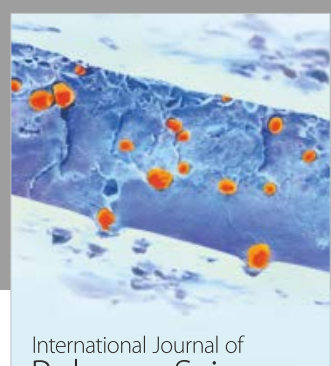

Polymer Science

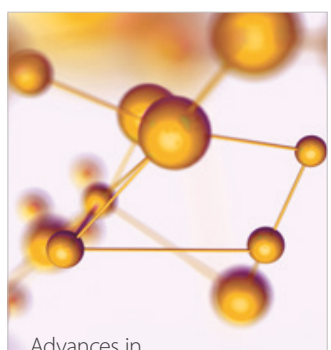

Physical Chemistry
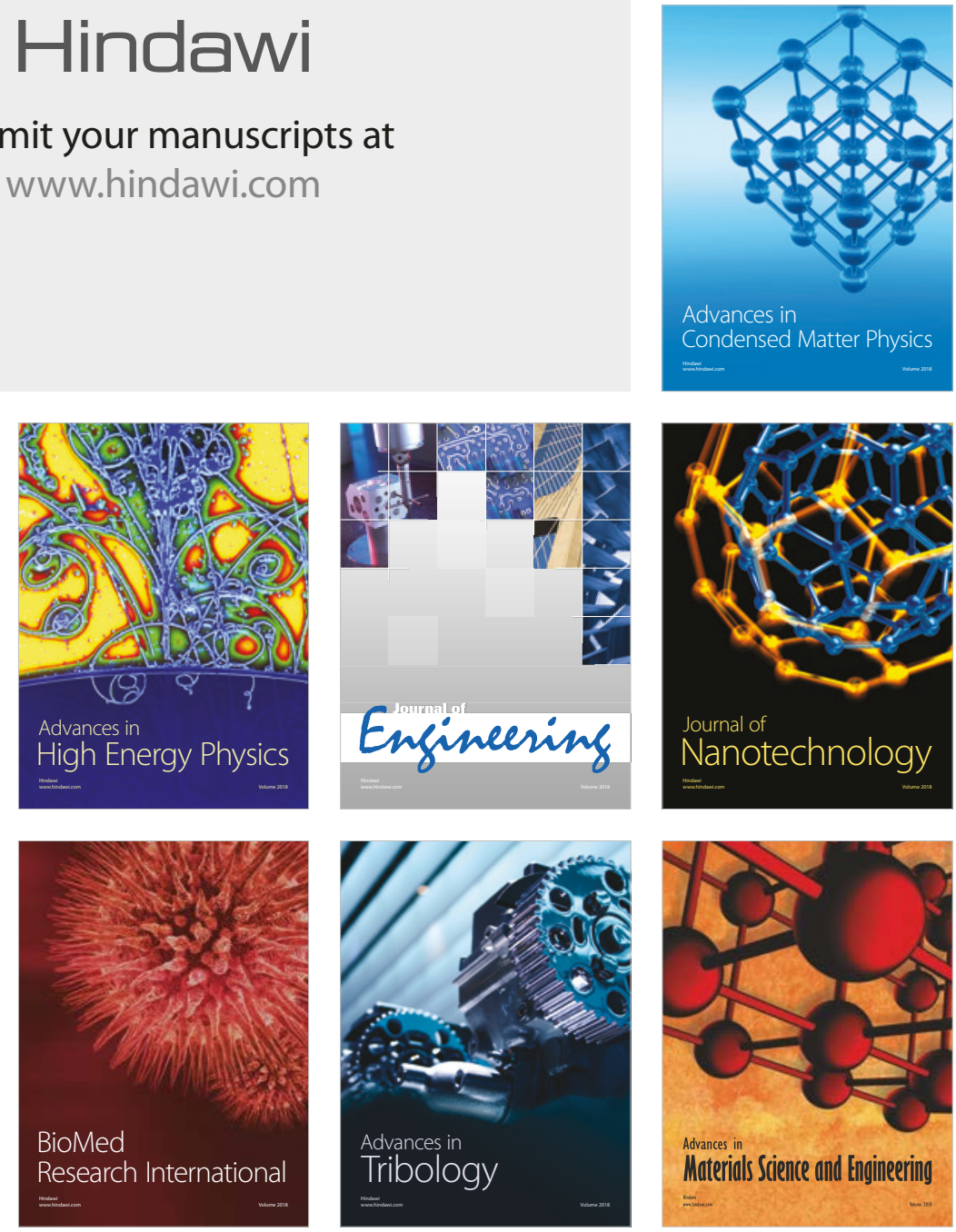